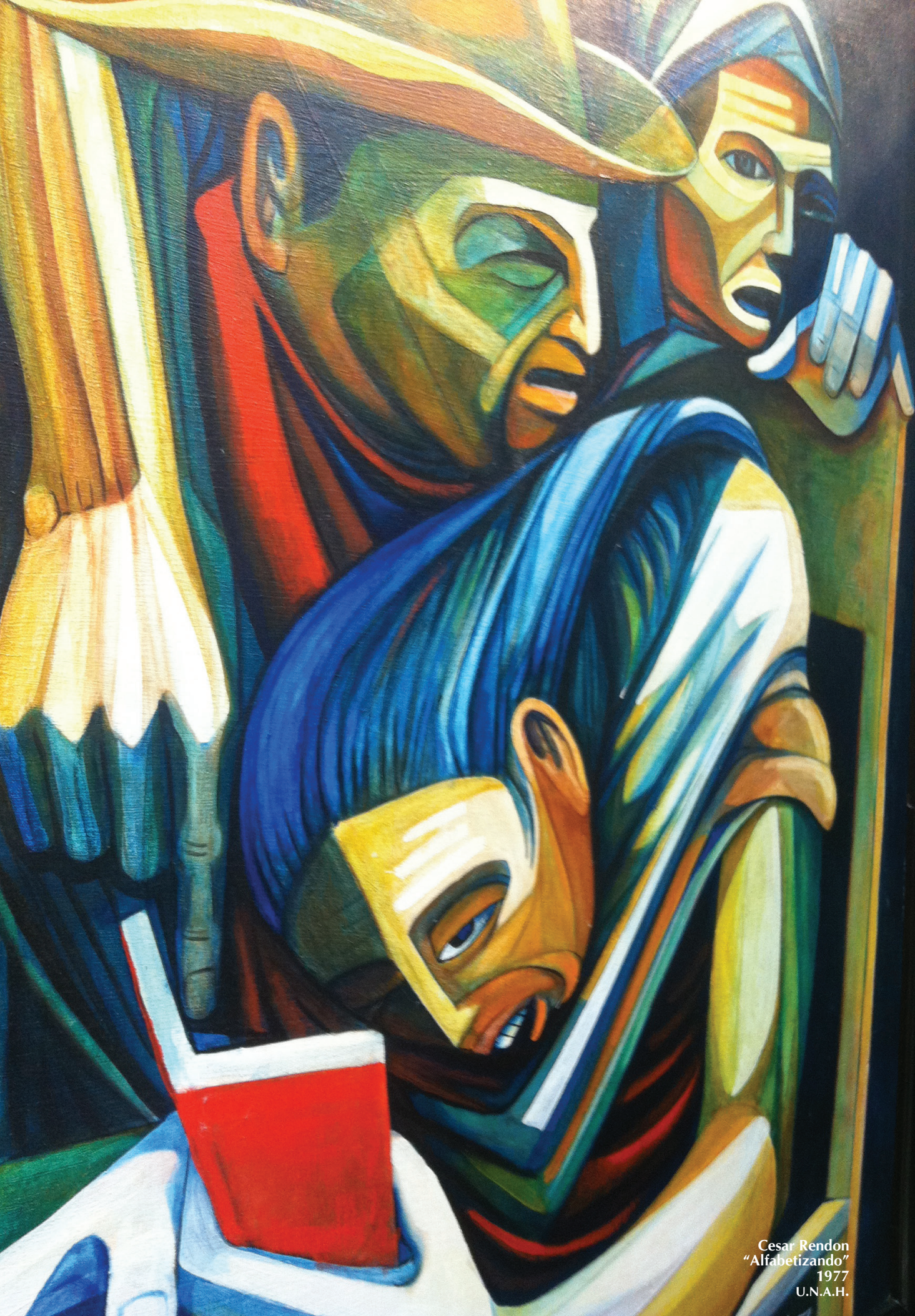




\section{LA TIPICIDAD EN LOS DELITOS CONTRA LOS DERECHOS DE AUTOR Y DERECHOS CONEXOS}

Por: Abog. Jeovanny Joel Hernández Sánchez- Profesor Investigador de la Facultad de Ciencias Jurídicas. Universidad Nacional Autónoma de Honduras. Especialista en Derechos de Autor y Derechos Conexos.Máster en Derecho Empresarial. E-Mail: jeo96@yahoo.com

\section{Resumen}

El aumento en la comisión de los ilícitos penales contra los Derechos de Autor y Derechos Conexos, se ha producido la mayoría de veces por el desconocimiento en la materia por parte de algunos de nuestros operadores de justicia, así como por la forma en que regula la acción penal el nuevo Código Procesal Penal; al calificar la acción de los delitos de la materia, como delitos de acción pública a instancia particular, lo que implica que de no existir denuncia por parte de los titulares de los derechos, el Ministerio Público no puede actuar de oficio. No cabe duda que esta regulación ha sido un retraso en la protección de los derechos en referencia, no obstante que el Estado se ha comprometido al firmar y ratificar acuerdos internacionales sobre la materia, como el Acuerdo sobre los Aspectos de Propiedad Intelectual relacionados con el Comercio (ADPIC).

Palabras Claves: Derechos de Autor y Derechos Conexos.Tipicidad. Leyes Penales en Blanco. Conductas típicas. Naturaleza Jurídica.

\section{Abstract}

The increase in the crimes of Copy rights and related rights, is due in the majority of the cases to the ignorance of the subject matter by some legal practitioners, and also by the way that the new Criminal Procedure Code regulates the criminal filing, qualifying the filing in relation to this kind of crimes as public offense filings by way of a personal and private filing, implying that in the absence of a complaint by the victim as a holder of the infringed right, office of the goverment attorney cannot act ex officio.

There is no doubt that this regulation has been a step backwards in the protection of the rights in question, notwithstanding that the Honduran State has signed and ratified international treaties on the matter, such as the Agreement on Aspects of Intellectual Property that are Trade- Related (ADPIC).

Keywords: Copy right and related rights, typicality, blank criminal laws, typical behaviors, legal nature. 


\section{INTRODUCCIÓN}

El presente trabajo de investigación fue desarrollado acerca de las generalidades sobre tópicos relacionados con la naturaleza y tipicidad de los actos que vulneran el derecho de autor y los derechos conexos.

Para el desarrollo del trabajo se tomó como base la consulta de textos, congresos, trabajos investigativos elaborados sobre el tema, así como los Convenios Internacionales que rigen la materia, como el Acuerdo sobre los Aspectos de los Derechos de Propiedad Intelectual relacionados con el Comercio. (ADPIC).

La intención del trabajo es dar una visión panorámica sobre aspectos relacionados con los problemas que plantea la tipificación de las acciones que atentan contra esta clase de derechos; como ser los relativos a sí los delitos deben regularse en el Código Penal o en las leyes especiales sobre Derecho de Autor y Derechos Conexos, así como los problemas que presenta el hecho que el legislador recurra a la utilización de leyes penales en blanco propiamente dichas y por qué se recomienda la regulación de estas acciones ilícitas a través de leyes penales completas.

También sobre la importancia de la represión de estos hechos ilícitos con sanciones penales lo suficientemente disuasorias, por su impacto negativo que entrañan no solo de los autores y titulares de derechos, sino a la difusión de la cultura, al comercio, a la industria, al desarrollo tecnológico y de los intereses generales de la sociedad.

En el desarrollo de la investigación se ha hecho una reflexión sobre aspectos doctrinarios generales acerca de la materia y su vinculación con algunas disposiciones establecidas en la legislación penal y sobre derechos de autor y derechos conexos de la República de Honduras.

\section{CAPITULO I GENERALIDADES}

La tendencia actual en materia del Derecho Penal es la influencia de las figuras de desjudicialización o despenalización de ciertas conductas delictivas para impedir que se produzca la saturación de esta rama del derecho y la situación no ha escapado con relación a la regulación de los delitos contra el derecho de autor y los derechos conexos, a tal grado que como lo expresa Antequera Parilli (1998), no obstante, las tendencias que consideran conveniente la despenalización de algunas conductas, sus defensores admiten la necesidad de punir al menos las acciones dolosas que infrinjan los derechos intelectuales, cuando incluso reconocen que delitos como la piratería se agrava en función de la tecnología. 
Esto tiene mucha similitud con lo que ocurre en el campo de los delitos contra la corrupción, que cada vez se vuelven más sofisticados con el avance de la tecnología, la cual es utilizada por los corruptos muchas veces sin dejar huella.

Según ANTEQUERA PARILLI (1998), en los años cincuenta, antes de surgir los mecanismos que hoy permiten la veloz reproducción de las obras o fácil transmisión o retransmisión de las emisiones alámbricas e inalámbricas, Mouchet y Radaelli destacaban que los ataques a los derechos autorales constituían por lo general una ofensa a la personalidad del autor (en la usurpación de la paternidad); una violación al patrimonio espiritual de la sociedad, como una lesión al decoro y la dignidad de un país, tal es el supuesto de las ediciones clandestinas de autores extranjeros. La situación se ha complicado en la medida que la tecnología facilita a bajos costos la fijación y duplicación de obras escritas incluidas los ordenadores de computador, las grabaciones sonoras y audiovisuales, así como la reemisión por radiodifusión o mediante conductores físicos de las transmisiones del organismo de origen, o la circulación de los bienes intelectuales protegidos a través de las redes digitales y las súper autopistas de la información.

Por tanto las infracciones contra los derechos autorales y conexos, no solo a-tenten contra los intereses particulares de autores, artistas, productores y radioemisoras, sino que perjudiquen también a la industria y al comercio vinculados con la protección, distribución publicidad y venta de bienes culturales y consecuencialmente, de las fuentes de empleo y del erario público.

Por lo que las sanciones penales en esta materia se justifiquen a la lesión causada al titular del respectivo derecho, al interés general y a la posición internacional de los Estados.

Todo lo anterior dio lugar a las resoluciones unánimes adoptadas por las delegaciones gubernamentales y los organismos internacionales con motivo de los dos foros convocados por la Organización Mundial de propiedad Intelectual OMPI, sobre la piratería de grabaciones sonoras y audiovisuales, (en 1981), y de radio difusión y obras impresas (1983), donde se destacó el daño que se generaba a las culturas nacionales, a la economía y al nivel de empleo, recomendando la previsión de sanciones efectivas, especialmente las de orden penal.

En cuanto al compromiso de sancionar penalmente las principales conductas infractoras del derecho de autor o los derechos conexos, figuran en el acuerdo de las ADPIC, el artículo 61, que preceptúa: "Los Miembros establecerán procedimientos y sanciones penales al menos para los casos de .... Piratería lesiva del derecho de autor a escala comercial. Los recursos disponibles establecerán las penas de prisión y/o la imposición de sanciones 
pecuniarias lo suficientemente disuasorias que sean coherente con el nivel de las sanciones aplicadas por los delitos de gravedad correspondiente. Cuando proceda entre los recursos disponibles figurarán también la confiscación, el decomiso y la destrucción de las mercancías infractoras y todos los materiales y accesorios utilizados predominantemente para la comisión del delito. Los miembros podrán prever la aplicación de procedimientos y sanciones penales en otros casos de infracciones de los derechos de propiedad intelectual, en particular cuando se cometa con dolo y a escala comercial".

Lo expresado en los ADPIC, otorga el marco de referencia que deben tomar en cuenta los Estados en sus legislaciones internas para la protección de los derechos de autor.

En base a los instrumentos internacionales mencionados, el doctor Antequera Parilli (1998), señala que la previsión penal de las conductas descansa sobre dos principios generales a saber:

1. Las sanciones deben ser lo suficientemente disuasivas, entre otras cosas para evitar, en lo posible, nuevas violaciones por parte del infractor.

2. La pena debe ser equivalente a la aplicable para otros delitos de similar magnitud.

En la legislación penal hondureña se puede decir que las penas son un tanto disuasivas, en vista que, a los delitos contra los derechos de autor y derechos conexos, se le asocia una pena tanto de reclusión como de multa considerable en cuando a su gravedad. Esta pena si bien no es igual, es equivalente podríamos decir, a los delitos de la misma magnitud, como el hurto de un bien mueble cuyo valor sobrepase los cinco mil lempiras ( $\mathrm{L}$ $5,000.00$ ), y de la estafa, entre otros, en cuanto a la pena privativa de libertad. Además, aparecen regulados en el mismo título de los delitos contra la propiedad. Si embargo, debido al aumento en la comisión de estos tipos penales, considero que el legislador debe sancionar estos tipos penales con penas mayores, porque de lo contrario estas acciones ilícitas seguirán en aumento, porque el Derecho Penal, no está cumpliendo con su finalidad de prevención. Resulta evidente que, los infractores continuarán incurriendo en la comisión de estas acciones ilícitas al saber que las sanciones con las que se castigan no son de gravedad, y aunado a ello el hecho de que la acción por estos delitos son de acción pública a instancia particular, de conformidad a lo establecido en el artículo 26 del Código Procesal Penal, lo que implica que el Ministerio Público, no puede accionar sino en virtud de denuncia por parte de la víctima. 
Si bien es cierto el artículo 26-A del Código Procesal Penal, faculta al Ministerio Público para que con el propósito de preservar pruebas y prevenir la continuación de la actividad infractora, pueda investigar o tomar otras medidas de observancia, de oficio, sin necesidad de una denuncia formal en los casos de piratería lesiva en materia de derechos de autor, considero que es mejor que se reforme el artículo 26 y se considere la acción en estos delitos como de acción pública, porque no cabe duda que el Ministerio Público, tal como está regulado actualmente y debido a la gran carga de trabajo y escasa logística, sólo le va a dar prioridad a los casos en que las víctimas presenten una denuncia formal.

El problema es que el país se ha comprometido al firmar y ratificar acuerdos internaciones, al combate de éstas acciones ilícitas so pena de ser sancionado en caso de incumplimiento, por parte de la Organización Mundial de Comercio, (OMC), por lo que en el caso en que no se proteja los derechos de personas extranjeros, que por la distancia no puedan presentar denuncias ante el Ministerio Público, estos pueden denunciar al Estado internacionalmente. Por tanto, tal como está regulado el tema de los acciones en materia de derechos de autor y derechos conexos, expone a Honduras a ser sancionado internacionalmente por incumplimiento de los tratados.

\section{CAPITULO II NATURALEZA JURIDICA}

El doctor Antequera Parilli (1998), resume las principales teorías acerca de la naturaleza de los delitos contra el derecho de autor y derechos conexos, así:

\section{Teoría de la Falsificación:}

Esta teoría fue acogida por la Ley Francesa de 1789, en la cual se inspiró en la legislación Italiana de 1882.

La Ley Francesa de 1957, mantenía esa orientación cuyo artículo 425 establecía: "Toda edición de escritos, de composiciones musicales, de dibujos, de pintura o cualquier otra producción impresa o grabada total o parcialmente, con infracción de las leyes y reglamentos relativos a la propiedad de los autores, es una falsificación y toda falsificación es un delito".

Según RAUL, GOLDSTEIN, citado por Antequera, (1998), la acción de falsificar tiene dos acepciones: por una parte significa adulterar o corromper; por la otra es sinónimo de contrahacer una cosa material o inmaterial. Contrahacer equivale a remendar, imitar o copiar, es decir, duplicar o reproducir. 
La falsificación podría explicar los delitos donde se infringe el derecho de reproduccion, pero no aquellos que atenten contra los morales de divulgación e integridad o el patrimonial de comunicación pública, si la acción no consiste en la reproducción indebida de ejemplares (El estreno no autorizado de una obra teatral o la retransmisión de una radio difundida.).

LEDESMA, (1992), expresa al respecto que la falsificación sólo podría admitir su existencia en los casos de reproducción abusiva, excluyendo el delito de plagio, sin pasar por alto los casos de una verdadera falsificación que constituyen las figuras penales previstas en el artículo 72 de la ley de Argentina, que establece como violación del derecho de autor al que edite clandestinamente una obra publicada o al que falsifique obras intelectuales entendiéndose como tal la edición de una obra ya editada ostentando falsamente ser el editor autorizado al efecto.

\section{Teoría de la defraudación.}

Para Antequera Parilli (1998), la concepción del derecho de autor como una simple propiedad, Ilevó a conceptuar a los delitos que lo infringen como de defraudación, no obstante que estos lesionan, fundamentalmente al patrimonio económico, al tiempo que existen violaciones contra los intereses de orden moral, como en los delitos de sustitución de la paternidad y en los de las mutilaciones de las obras.

Esta tesis ha sido criticada, además por falta de rigor científico, ya que en el fondo de la defraudación está siempre el fraude, el cual equivale a engaño con una repercusión patrimonial, de modo que se le emplea arbitrariamente para designar y clasificar infracciones que no tienen nada de común entre sí, ni con el mencionado delito en los códigos penales.

A este respecto LEDESMA, (1992) expresa que, lo establecido en los artículos 71 y 72 de la Ley autoral Argentina, sobre la defraudación, ha conducido erróneamente al tribunal a exigir que la comisión de los delitos contra el derecho de autor debía quedar sometidas a los requisitos estatuidos sobre dichos tipos por el Código Penal. Pero, que tomada en su verdadero alcance la aludida figura, resulta de naturaleza genérica.

Consecuentemente, se trata de un vocablo calificante que carece del significado preciso que le atribuye el Código Penal, adquiriendo, en vez, el común, que no es otro como lo ha expresado y lo viene sosteniendo la doctrina Argentina, que es la actividad ilícita realizada por el agente en perjuicio de la obra del autor, que tiene por finalidad hacer aparecer un hecho como verdadero. 
Asimismo en el $\mathrm{V}$ Congreso Internacional sobre la Protección de los Derecho Intelectuales, se señaló que la tipificación de los delitos en Argentina, a través de la ley 11,723, fue muy criticada por los autoralistas, porque se quedaban impunes las más graves lesiones al derecho de autor. Ya que se construyeron fallos que exigían que concurrieran los requisitos de la estafa para la existencia de los delitos contra la propiedad intelectual previstos por la ley.

\section{Teoría del hurto:}

ANTEQUERA PARILLI (1998), expresa que la teoría del hurto, equivocadamente admitida por Chiossone, también parte de la errada concepción del derecho de autor como una propiedad, y por tanto resulta igualmente forzada la ubicación allí de ciertos ilícitos contra los derechos intelectuales, incluso en sus variantes de hurto impropio o específico.

Por tanto, no se puede equiparar los delitos contra el derecho de autor con el hurto, ya que los elementos que se requieren para que se configure este hecho delictivo según los Códigos Penales como el de Honduras, son los siguientes:

a. Quien se apodere de un bien mueble ajeno

b .Sin la voluntad de su dueño

c .Sin violencia, intimidación en las personas o fuerza en las cosas.

Es imposible como dice el Doctor Antequera, (1998), la adaptación de esta figura a supuestos de hecho donde no aparecen los elementos de quitar, y trasladar de lugar; si no en cualquier caso, el aprovechamiento de la forma de expresión de las ideas o de las prestaciones, producciones y emisiones protegidas en el marco de los derechos conexos. LEDESMA, (1992), manifiesta que los delitos en examen han sido incluidos por muchos autores en la figura clásica del hurto o bien en la del hurto impropio. Pero que ni uno ni otro son aplicables, puesto que el primero supone una transferencia material de la cosa y el pensamiento no es susceptible de exclusiva apropiación material; y que el segundo, resulta también ajeno al derecho de autor porque solo en casos contados como en el fonograma se presenta el ánimo de lucro ilícito.

Por lo antes expuesto resulta inadmisible en las legislaciones como la hondureña, esta teoría del hurto, porque como lo expresa Ledesma, no se puede hablar en estas legislaciones de hurto en la propiedad intelectual, desde que se supone el aprovechamiento ilícito de una cosa mueble total o parcialmente ajena y no de un bien inmaterial. 


\section{Teoría de la usurpación:}

Tal como lo Expresa Antequera Parilli (1998), la usurpación tiene varios significados: "en materia de propiedad se le entiende como el despojo o alteración de los derechos reales ajenos: en cuanto a los intereses inmateriales, a la apropiación de la forma o la reputación de otro: pero en ciertos sistemas penales se le concibe de forma distinta, para sancionar la arrogación indebida de funciones, títulos u honores".

Podría explicarse en el marco de esta teoría la figura del plagio, como usurpación de la paternidad de la obra, pero no es posible ubicar allí a los atentados contra el derecho de divulgación(si se indica el nombre del autor), la integridad de la obra, la reproducción no autorizada o la comunicación pública sin consentimiento del titular del respectivo derecho.

LEDESMA (1992), partiendo del concepto que da la real academia de usurpación, la cual define como la simple posesión de hecho sin título legítimo, o el goce injusto y fraudulento de alguna cosa o derecho de que uno se ha apoderado de mala fe, por violencia o artificio en perjuicio del público o de los particulares, manifiesta que sobre tales condiciones el agente actúa en este delito ejerciendo derechos pertenecientes a terceros, pretendiendo así sustituir al autor o aparecer como tal, beneficiándose con la utilización de la obra ajena o perjudicando su integridad.

Es el caso establecido en la Ley Argentina, que expresa que será reprimido quien atribuyéndose indebidamente la calidad de autor, derechohabiente o la representación de quien tuviese derechos, hiciere suspender una representación o una ejecución pública lícita. Es lo que constituye la usurpación de la paternidad de una obra al manifestarse una ilícita sustitución de la calidad autoral.

No ocurre lo mismo con la edición no autorizada, cambiando el título de la obra o alterando su texto, puesto que no se pretende con dichas maquinaciones dolosas reemplazar al autor.

\section{Teoría de los delitos sui generis:}

PICAR, (citado por ANTEQUERA PARILLI, 1998) expresa que "la clasificación tripartita de los derechos (reales, personales y obligacionales), es incompleta, pues existe una cuarta categoría: los derechos intelectuales o iure intelectuales. Se ha sostenido que los derechos de autor son sui generis, atendiendo a la especialidad y autonomía de la disciplina, de modo que los hechos punibles que lo afectan no pueden asimilarse a las 
figuras comunes, particularmente cuando estas se dirigen a proteger derechos de distinta naturaleza, especialmente por su compleja estructura moral y patrimonial."

\section{CAPITULO III LA TIPICIDAD}

Se dice que una acción es típica cuando puede subsumirse en un tipo del Código Penal o de una Ley Penal Especial, es decir, cuando cumple los requisitos exigidos por un tipo penal.

El procedimiento que se sigue para saber si una acción es típica, es el siguiente:

a. En primer lugar hay que descomponer el tipo penal en el cual suponemos que se subsume el hecho, en sus partes para ver cuales son los elementos del mismo,

b. Determinar si en el caso planteado, se dan o no los requisitos del tipo.

Sólo cuando el hecho cumple con los requisitos exigidos por el tipo se puede decir que la acción es típica y por tanto se subsume en ese tipo, de lo contrario estaremos frente a una acción atípica, es decir, no punible dentro del campo penal.

Los elementos o requisitos, reciben el nombre de características, y estas pueden ser:

1.Descriptivas: que están formadas por sucesos que se dan en el mundo exterior, y cuya finalidad es describir en forma clara y determinante en que consiste el hecho punible, a manera de evitar que el Juez entre a tipificar varios delitos.

2.Normativas: Son aquellas en que el legislador le otorga la tarea al Juez de interpretar determinados términos, recurriendo para ello a los medios de interpretación de la ley penal.

3.Subjetivas: son aquellas que se refieren a una actitud interna del sujeto es decir, que se requiere que el autor haya actuado con un determinado propósito o intención.

4.Negativas: son aquellas en que el legislador se vale de expresiones negativas para circunscribir la conducta punible. 
Es de hacer notar que, no todos los tipos delictivos contienen todas estas características, por lo que no se requiere que necesariamente concurran todas ellas. Por otra parte, es de mencionar que existen tipos penales con pluralidad de hipótesis y basta para que la acción sea típica que se cumpla uno solo de ellos.

Ahora bien, los aspectos relativos a la tipificación de los delitos en materia de Derechos de Autor y Derechos Conexos, se ha turnado a las legislaciones de cada país, siendo común en la mayoría de los países establecer sanciones penales para aquellos delitos que atenten contra los derechos de autor y derechos conexos, aunque la gravedad de tales sanciones varíen de un país a otro. Esta obligación de establecer delitos contra los derechos de autor y derechos conexos, tiene su fundamento en el artículo 61 de los ADPIC, que como expresé anteriormente por medio de este los Estados contratantes se obligan a establecer procedimientos y sanciones penales al menos para los casos de piratería lesiva del derecho de autor a escala comercial.

Resulta importante que los países establezcan tipos penales con sanciones suficientemente disuasorias porque de lo contrario de nada serviría que se aprobaran leyes protectoras del derecho de autor, si su infracción no diera lugar en aquellos casos de gravedad, a la imposición de sanciones penales, y esto es así, ya que la pena debe de operar como última ratio, es decir, sólo cuando el ilícito sea de mayor gravedad e importe un grave daño a los intereses de los autores y de los intereses generales de la sociedad. Llevar al campo del Derecho Penal indiscriminadamente todas las conductas, se produciría lo que se conoce como fenómeno de inflación del derecho y recargo del trabajo en los tribunales ordinarios de justicia.

La tipificación de los delitos contra el derecho de autor y derechos conexos en algunos países se realiza en las propias leyes especiales, por ejemplo; Costa Rica, Bolivia, Perú, Venezuela, etcétera, mientras que en otras legislaciones la tipificación se encuentra en los Códigos Penales, ejemplo; Guatemala, Brasil, Honduras.

En el caso particular de Venezuela al regular los delitos contra los derechos de autor, toma en algunos casos lo que se conoce como Principio de Subsidiariedad expresa, al manifestar que "siempre que el hecho no constituya un delito más grave previsto en el Código Penal u otras leyes especiales, será castigado con prisión de seis (6), a dieciocho (18), meses....", por lo que este delito se aplicará sólo en defecto de lo expresado en el Código Penal.

Otros caso como el Código Penal de Honduras, con sus reformas introducidas con ocasión de la implementación del CAFTA, que reformó por adición el artículo 248, tipifica 
Ios delitos contra el Derecho de Autor y Delitos Conexos de la siguiente manera: "Artículo 248: "Quien viole los derechos de los autores de obras literarias o artísticas, o los derechos Conexos protegidos por las leyes del Derecho de Autor y Derechos Conexos, será sancionado con reclusión de tres (3) a seis (6) años, más una multa de CINCUENTA MIL (L. 50,000.00) a CIEN MIL LEMPIRAS (L. 100,000.00)". En las mismas penas incurrirá, quien importare, exportare o almacenare ejemplares de dichas obras o producciones o ejecuciones sin la referida autorización".

Artículo 248 A: "Con las mismas penas del artículo 248 anterior, sarán sancionadas las personas naturales o jurídicas que sin la autorización de los respectivos titulares de los derechos de autor o derechos conexos utilicen con fines comerciales, señales de televisión transmitidas por señales de satélite o reproduzcan o proyecten videos, películas u otras obras análogas que, por su naturaleza estén o deban estar protegidas por la ley en la materia. Con las mismas penas serán sancionados quienes utilicen las frecuencias del espectro radioeléctrico sin autorización de la autoridad correspondiente".

Artículo 248-B : “En las mismas penas del artículo 248, incurrirá, quien sin autorización de los respectivos titulares de los derechos de autor y de los derechos conexos eluda o evada cualquier medida tecnológica efectiva que controle el acceso a una obra, interpretación o ejecución, o fonograma, u otra materia objeto de protección. Se excluyen de responsabilidad penal, al que ejecute las actividades exceptuadas en el Título VI, Capítulo II, Sección I de la Ley de Implementación del Tratado de Libre Comercio, República Dominicana, Estados Unidos".

Artículo 248-C: "En las mismas penas del artículo 248 incurrirá, quien con el fin de lograr una ventaja comercial o ganancia financiera privada y a sabiendas que este acto podrá inducir, permitir, facilitar o encubrir una infracción de un derecho de autor o derechos conexos:

1.- A sabiendas suprima o altere cualquier información sobre gestión de derechos, o,

2.- Distribuya, importe para distribución, transmita, comunique o ponga a disposición del público copias de obras, interpretaciones o ejecuciones o fonogramas, teniendo conocimiento que la información sobre gestion de derechos ha sido suprimida o alterada sin la autorización del titular del derecho. 
Se excluyen de responsabilidad penal, al que ejecute las actividades exceptuadas en el Título VI, Capítulo II, Sección II de la Ley de Implementación del Tratado de Libre Comercio, República Dominicana, Estados Unidos".

Estas leyes son leyes penales en blanco propiamente dichas, porque ambas tienen incompleto el precepto o presupuesto, es decir, que para completarlos hay que remitirse a las disposiciones de la Ley de Derechos de Autor y Derechos Conexos. Hecho que para mí no es correcto, porque la mejor forma para tipificar estos delitos debe ser regularlos de una manera completa bien sea en la Ley Especial de Derechos de Autor o en el propio Código Penal, ya que por su complejidad, y por la forma en que están tipificados pueden dar lugar a la incertidumbre que atenta contra el principio de legalidad, bien sea en perjuicio de los autores o de los mismos imputados.

Recordemos que esta es un materia especial y que por tanto existe desconocimiento por algunos operadores de justicia, lo cual puede permitir que se cometan abusos en el sentido de que se consideren como delito acciones o hechos que no lo son o que se dejen de penalizar acciones que si constituyen delito, pero como los tipos penales son abiertos se corren estos riesgos, por lo que resulta necesario que los tipos penales sean definidos en forma completa y bien determinada para que no exista tal incertidumbre sobre qué acciones son las que constituyen delito, garantizando con ello el principio de legalidad en materia penal. "Nullun Crimen sine Lege".

Para el caso en España, como lo señala ALEJANDRO GONZALES GOMEZ, (1998), la introducción o precisión, a partir de 1987, de la (s) conducta (s) típica (s) supuso, en opinión de un amplio sector de la doctrina, el abandono definitivo de la técnica legislativa de la ley penal en blanco. No obstante lo anterior, es decir que el nuevo sistema de protección penal de la propiedad intelectual se recoge en una norma penal completa, en el sentido de contener( al menos ) el núcleo esencial del comportamiento delictivo "Supuesto de hecho", más la pena que le corresponde, "Consecuencia jurídica", subsiste necesariamente una vinculación formal interpretativa con la legislación especial.

Agrega que, desde el punto de vista formal, el artículo 272 del Código Penal, remite para determinación de la responsabilidad civil, el cese de la actividad ilícita e indemnización de los daños y perjuicios a las disposiciones de la ley de propiedad intelectual, (artículos 133 a 138). Reenvío que en todo caso, habrá que considerar como una técnica (de economía) normativa y en modo alguno resabio de norma penal en blanco. Este ligamento interpretativo, en cierta forma ineludible, viene determinado no sólo por el rico contenido de elementos normativos que procedentes o equivalentes a los de la ley de propiedad intelectual, se incorporan a la legislación penal, sino por otros factores. Entre estos, 
importa destacar la concreta realidad normativa de la propiedad intelectual, así como la concatenación temporal y teleológica de su reforma (civil y penal).

Por otra parte, como puede apreciarse en la legislación penal hondureña, los delitos contra el derecho de autor y los derechos conexos, están regulados bajo un mismo título, "DELITOS CONTRA LAS PROPIEDADES ESPECIALES". Asimismo, están sancionados con las mismas penas; en cambio en otros países, los ilícitos penales contra los derechos conexos han sido objeto de regulación separada, por ejemplo en Francia, donde en 1985 se incorporó un artículo especial en el Código Penal (el artículo 426-1) y en Argentina, donde por ley de 1989 se introdujo en la ley de propiedad intelectual el artículo 72 bis que tipifica la reproducción no autorizada de fonogramas (piratería fonográficas); en ambos ejemplos, las sanciones son iguales a las previstas para reprimir los ilícitos penales contra los derechos de los autores.

\section{CAPITULO IV REQUISITOS PARA LA TUTELA LEGAL}

Para LIPSZYC, (1993:), los requisitos para la tutela legal son los siguientes:

a) Que se trate de una obra protegida, por aplicación de los principios generales sobre la protección de las obras.

b) Que la utilización no se haya efectuado al amparo de una limitación del derecho de autor o de los derechos conexos.

c) Que el plazo de protección se encuentre vigente, es decir, que no se haya extinguido el derecho.

d) Que la conducta del agente se adecue a una figura típicamente incriminada.

e) La existencia del dolo en el agente.

f) El ánimo de lucro no es un elemento constitutivo de las figuras delictivas contra el derecho de autor y los derechos conexos, excepto cuando la norma que tipifica el delito lo exige expresamente (por ejemplo, en Argentina, artículo 72 bis, a, b y c, referidos a distintas formas de piratería). 
En cuanto al dolo es importante señalar que conforme lo expresa el causalista,SEBASTIAN SOLER, (1951), existe dolo no solamente cuando se ha querido un resultado, sino también cuando se ha tenido conciencia de la criminalidad de la propia acción y a pesar de ello se ha obrado.

\section{CAPITULO V LAS NORMAS PUNITIVAS. LA TIPIFICACION "ABIERTA".}

Tal como lo expresa (LIPSZYC,1993), en Francia y en otros países que siguen el criterio Francés, (Bélgica, Argelia, Camerún, Senegal etc.) las infracciones del derecho de autor son genéricamente denominadas "CONTREFACON". Según el Código Penal Francés (arts. 425 y 426) toda edición, reproducción, representación o difusión de una obra en violación de los delitos de autor es una Contrefacon y toda contrefacon es un delito. (RADAELLI Y MOUCHET,1953) señalan que de acuerdo con la doctrina y jurisprudencia francesa (citan a Huard), para que exista un ataque a los derechos intelectuales deben encontrarse reunidos los cuatro requisitos siguientes:

a) Que se trate de un derecho de propiedad literaria o artística.

b) Que ese derecho haya sido ejercido (no es necesario demostrar perjuicio),

c) Que ese derecho haya sido ejercido por una persona que no es el verdadero sujeto del derecho;

d) Que el derecho de que se trata haya sido ejercido sin consentimiento de aquel que es el verdadero sujeto.

Según (Claude Colombet,1997) contrefacon, es un término amplio que puede definirse, casi universalmente como un ataque a los derechos de autor, y por de pronto a sus derechos patrimoniales, con excepción del droit de suite, sancionado generalmente con una indemnización de daños e intereses.

En Portugal, el Código de Derecho de Autor y Derechos Conexos de 1985 incrimina en el artículo 195 el delito de usurpación y en el artículo 196, el de contrafaccao, en los siguiente términos: "art. 195 (1) Cometerá el delito de usurpación quien utilice sin autorización del autor o del artista, del productor de fonogramas y de videogramas y del organismo de radiodifusión, una obra o una prestación en una de las formas previstas en el presente código" y, "artículo 196 (1) cometerá el delito de contrafaccao, quien utilice fraudulentamente como prestación o creación suya, una obra, la prestación de un artista, un fonograma, un videograma o una emisión de radio difusión, que sea la simple reproducción total o parcial de una obra o de la prestación de otro, divulgada o no, o que sean 
tan parecidas que no presenten ninguna individualidad propia".

En los países de Latinoamérica también se advierte una tendencia a una tipificación "abierta" (por ejemplo Brasil, Código Penal artículo 184, Argentina artículo 71, Chile artículo 78 y 79) que debe relacionarse con las dificultades que el continuo avance de la tecnología plantea en materia de derecho de autor y derechos conexos para prever anticipadamente todas las modalidades delictivas.

Zaffaroni, (citado por LIPZYC, 1993), expresa que ambos extremos ponen en peligro las garantías penales o dejan desprotegido el bien jurídico, pueden conducir igualmente a situaciones negativas, por lo cual se recomienda, en cuanto sea posible, que la tipificación de los delitos que afectan los derechos de autor y conexos se describan con precisión tomando en cuenta sus peculiaridades y reglas propias de la elaboración de la ley penal.

Para ANTEQUERA PARILLI (1998), la tipicidad como regla general para todos los ilícitos penales en derecho de autor y derechos conexos, parte de tres requisitos fundamentales a saber:

1. Que se trate de un derecho intelectual protegido por la ley;

2. Que la obra, producto, interpretación o emisión, según los casos, sean utilizados sin la autorización del titular del respectivo derecho, o bajo el amparo de una excepción legal expresa.

3. Que esté vigente el período de protección legal, a menos que en un supuesto concreto la ley disponga otra cosa". Estos requisitos son similares a los expresados por RADAELLI Y MOUCHET.

\section{CAPITULO VI LAS CONDUCTAS TIPICAS}

Según LIPZYC, (1993), las conductas típicas pueden dividirse en tres clases:

1. Lesiones al derecho moral.

2. Lesiones a los derechos patrimoniales

3. Lesiones mixtas (al derecho moral y a los patrimoniales).

\section{Lesiones al derecho moral.}

"Las formas comisivas de las lesiones al derecho moral, no relacionados con el derecho 
patrimonial, son aquellas en que el agente, debidamente autorizado para utilizar la obra ya sea en virtud de un contrato o de una licencia no voluntaria o en general, de una limitación legal, lo hace sin respetar los derechos del autor a la paternidad o a la integridad de la obra.

La lesión al derecho de paternidad tiene lugar cuando se omite el nombre del autor (o cuando este no quiso permanecer anónimo) o se lo cambia (por ejemplo sí el autor eligió un seudónimo y la obra se reproduce o se comunica al público consignando el nombre verdadero, o si quiso permanecer anónimo y se indica su nombre o seudónimo).

La lesión al derecho de respeto y a la integridad de la obra se verifica cuando se efectúan transformaciones (traducciones, adaptaciones, reducciones etc. y en general cuando se introducen cambios o agregados), sin autorización al efecto o cuando se exceden los límites de la transformación autorizada (por ejemplo sí se autorizó una traducción de la obra y también se la adapta, se le reduce, se le hacen agregados etc. O sí se autorizó la adaptación estrictamente necesaria para pasar de un género a otro, del teatro a la televisión etc. Y se hace una versión libre"

Para LEDESMA, (1992), la transgresión del derecho moral se presenta cuando entra en conflicto el derecho de paternidad, de inédito, intangibilidad, individualización o identidad de la obra.

La ley hondureña regula estos casos en el artículo 138: 1, 2, 3) "Incluir en una obra suya como propia, fragmentos o partes de una obra ajena protegida; 4) Apropiarse del título original ajeno protegido; 5) Pretender inscribir como suyo, obra literaria, artística, fonograma, interpretación, ejecución o transmisión ajena".

\section{Lesiones a los derechos patrimoniales}

Para LIPZIC, (1993), La regulación de la tutela penal de los derechos patrimoniales del autor describe como delitos las infracciones al derecho de reproducción, al derecho de comunicación pública, representación, exhibición cinematográfica, radiodifusión, cabledistribución, etc.) y al derecho de transformación de todo o en parte de las obras literarias, musicales y artísticas.

Para LEDESMA, (1992), "la transgresión al derecho patrimonial tiene lugar cuando entra en convulsión, entre otros el derecho de publicación, reproducción o explotación de la obra".

La legislación hondureña, describe las violaciones al derecho patrimonial en el mismo artículo 138,1$)$ La presentación, ejecución o audición pública o la transmisión, comuni- 
cación radiodifusión y/o distribución de una obra literaria o artística protegida, sin la autorización de su autor, herederos o derechohabientes, excepto en los casos consignados en la presente ley; 2) Transmisión o la ejecución pública de fonograma protegido, sin la autorización de su productor, excepto en los casos consignados en esta ley; 3, 4, 5, 6) Reproducir o alquilar obras literarias, artísticas o científicas protegidas, sin autorización de su autor; 7) Reproducir o alquilar copias de fonogramas protegidos sin la autorización de su productor; 8) Fijar y reproducir o transmitir interpretaciones o ejecuciones, protegidas sin la autorización del artista; 9) Fijar y reproducir o retransmitir emisiones protegidas sin autorización de los organismos de radiodifusión; 10) La impresión del editor de mayor número de ejemplares que el convenido con el titular del derecho, salvo el exceso que sea necesario para dar cumplimiento a las obligaciones contenidas en esta ley; 11) La adaptación, transformación, traducción, modificación o incorporación de una obra ajena o parte de ella, sin la autorización del autor o sus causahabientes;13) Vender, distribuir, alquilar, importar o exportación de ejemplares de obra o fonograma protegido fraudulentamente reproducido.

3. Lesiones mixtas (al derecho moral y a los derechos patrimoniales)

Para LIPZIC, (1993), bajo esta rública nos referiremos solo a aquellas conductas que siempre extrañan una agresión a los intereses de orden moral y a los de orden patrimonial; son los casos de publicación no autorizada de una obra inédita, de publicación no autorizada de una obra respecto de la cual el autor ha ejercido el derecho de retracto o arrepentimiento y de plagio. Dejaremos de lado aquellas otras en que concurren violaciones de orden moral y a los derechos patrimoniales, por ejemplo la edición no autorizada de una novela omitiendo el nombre del autor y/o alterando el texto, pero que no van nece-sariamente unidas. La situación de la publicación no autorizada de una obra inédita o de una obra respecto de la cual el autor ha ejercido el derecho de retracto o arrepentimiento se explican por si mismas, se infringen los derechos morales de retracto o arrepentimiento, además de los derecho patrimoniales de reproducción y de comunicación pública.

La ley hondureña contempla estos casos en el artículo 138, numeral, 12) al expresar:"La publicación de obra ajena protegida con el título cambiado o suprimido o con el texto alterado, como sí fuera de otro autor".

Como expresa ANTEQUERA PARILLI (1998), sobre estos principios descansa la obligación del legislador de definir con claridad los tipos delictivos para evitar, por una parte, que ciertas acciones merecedoras de sanción se excluyan del tipo; y por la otra, que 
conductas menores o benignas, susceptibles de represión a través de sanciones civiles y administrativas, queden incluidas en la norma penal. De allí la critica a los (tipos penales abiertos) o en blanco, es decir, que no especifican con precisión el supuesto reprochable, sino que dejan al Juez la tarea de individualizarlas con vistas a las disposiciones generales existentes en la misma ley u otras leyes, como ocurre cuando la norma contempla una sanción penal "quien atente dolosamente o con culpa grave contra el cumplimiento de esta ley (v.gr. Guatemala). Esa modalidad ha sido motivo de severas objeciones por la doctrina y provocado, incluso anulaciones judiciales.

Es evidente entonces la conveniencia de una tipicidad precisa, con indicación clara de la conducta punible y del derecho transgredido, de ser posible con indicación de sus modalidades que conforman ese derecho o una remisión expresa al dispositivo atinente a las formas de uso cuya realización son objeto de la represión penal.

GOMES Y QUINTERO (1998), señalan que el artículo 534 de la legislación española, enumera un catálogo ciertamente amplio de conductas penalizadas. Todas tienen un objeto común; la obra literaria, artística o científica o su transformación, interpretación o ejecución.

¿Cuáles son esas conductas? Basta con leer la ley: reproducir, plagiar, distribuir, comunicar (todo ello públicamente), importar, exportar o almacenar (obras que hayan sido objeto de aquellas acciones). Algunas de estas conductas son por su parte definidas por la Ley de Propiedad Intelectual (artículo 17 y siguientes).

CRISTINA BUSCH (1995), expresa que, las recomendaciones político- jurídico para un modelo ideal de tipificación penal en materia de derecho de autor, se estructuran sobre dos líneas de argumentación: la explicación del modelo básico concretando sus cinco puntos esenciales y la especificación de los principios fundamentales de este modelo.

1.- Concepto básico de un modelo de protección penal de los derechos de autor.

a) Necesidad de un sistema de instrumentos eficaces para persecución y la sanción.

Un modelo de tutela penal tendría que contar con instrumentos eficaces (especialmente el embargo y la destrucción de los objetos o instrumentos ilegales) para dar respuesta a los antes mencionados problemas que suscitan la persecución y sanción práctica de la piratería intelectual.

2. - Especificación de los principios fundamentales de un modelo de protección de los derechos de autor. 


\section{a) Sistemática}

Desde el punto de vista criminológico y derecho comparado, se recomienda la inclusión de los tipos penales contra el derecho de autor en el Código Penal y se rechaza la ubicación sistemática en la ley especial de derechos de autor.

\section{b) Técnica legal}

Como corresponde al objetivo de una iniciativa armonizadora (una protección penal eficaz y aplicable en la persecución práctica) se concretan las infracciones graves y los bienes jurídicos protegidos. Una separación entre tipo basico y agravado resulta aconsejable.

La técnica de norma penal en blanco no sólo es criticable desde el punto de vista constitucional, como infracción del principio de certeza (deducido del principio de legalidad y postulado de seguridad jurídica), sino que implica además el peligro de hipertrofia punitiva que lleva a que las autoridades se vean disuadidas al combate contra la piratería intelectual.

\section{c) Tipo subjetivo}

Condición de una persecución eficaz de la (piratería intelectual) es que las disposiciones penales puedan ser aplicadas sin elevados requisitos para probar la concurrencia del dolo. Con la dimensión internacional que ha ido ganando esta forma de criminalidad, ha aumentado también la complejidad de las cuestiones jurídicas. Por lo tanto, existe el peligro de que el infractor pueda lograr a menudo la suspensión del proceso aduciendo por ejemplo el haberse equivocado con respecto a la protección existente o al desconocimiento sobre la protección de la mercancía para ser protegida en tanto obra sometida al derecho de autor.

Al mismo tiempo, no es postulable la introducción de un tipo imprudente por que, como consecuencia de esta incriminación, los comerciantes, empresarios de la distribución por cable, propietarios de videoclubs, etc. se verían sometidos a deberes especiales de precaución. Tal aumento del deber de precaución significa sobrecargar a la economía privada con tareas de investigación

\section{d) Sistema de sanción}

La conminación y la imposición exclusiva de la multa pecuniaria son considera ciones como inapropiadas para luchar contra la (piratería intelectual moderna). Especialmente para el tipo agravado se postula su aplicación acumulativa a la pena privativa de libertad. 
En general se impone por principio la equiparación de las infracciones de la pro piedad intelectual a las infracciones de la propiedad material en lo que a la medida de pena se refiere.

\section{CONCLUSIONES}

1.- La protección de los derechos de autor y derechos conexos, encuentran su marco re-ferencial o su fundamento en el artículo 61 del Acuerdo sobre Los Aspectos de Los Derechos de Propiedad Intelectual relacionados con el Comercio. ( ADPIC ), el cual expresa que Los Miembros establecerán Procedimientos y sanciones penales al menos para Los casos.... de piratería lesiva del derecho de autor a escala comercial. Los recursos disponibles comprenderán la pena de prisión y/o la imposición de sanciones pecuniarias suficientemente disuasorias que sean coherente con el nivel de las sanciones aplicadas por delitos de gravedad correspondiente. Por lo que los países tendrán que adecuar sus legislaciones al mismo.

2.- La represión penal de los actos que vulneran los derechos de autor y derechos conexos, se justifica por el perjuicio que entrañan a la libre difusión de la cultura, de la industria, del comercio, del avance tecnológico y la sociedad en general.

3.- La tipificación de los delitos debe hacerse de una manera clara, precisa, y bien determinada, de forma que se exprese meridianamente en qué consiste el hecho punible.

4.- Es recomendable que el legislador al momento de tipificar los delitos contra el derecho de autor y derechos conexos, lo haga con leyes penales completas, es decir, sin recurrir a la utilización de leyes penales en blanco propiamente dichas porque esto puede dar lugar a incertidumbre y a un abuso del arbitrio por parte de los jueces, lo cual confrontaría con el principio de legalidad arraigado en nuestro ordenamiento jurídico, además, del daño que se podría causar tanto a los autores como a los imputados.

5.-También es importante que nuestros legisladores repriman estas conductas delictivas con sanciones penales lo suficientemente disuasorias, porque de lo contrario el respeto de los derechos de autor y derechos conexos serían un hazme reír, como está sucediendo en la realidad. Por lo que se hace necesario introducir una reforma al Código Procesal Penal, para que los delitos contra el derecho de autor y derechos conexos, sean de orden público, y no de acción pública a instancia particular. 


\section{BIBLIOGRAFIA}

Acuerdos sobre los aspectos de los derechos de propiedad intelectual relacionados con el comercio ADPPIC . (1994).

Antequera Parilli, R. (1998). Derecho de Autor. Caracas: Dirección Nacional del Derecho de Autor.Venezuela.

Busch, C. (1995). La Protección Penal de los Derechos de Autor en España. Barcelona: Cedecs.

Gómez Benites, J., \& Gonzalo, Q. La protección penal de los derechos de autor y conexos. Cevitas S.A.

Gonzalez Gómez, A. (1998) El tipo básico de los delitos contra la propiedad intelectual. TECNOS. España.

Ledesma, J. (1992). Derecho penal intelectual. Buenos Aires: Universidad.

Lipszic, D. (1993). Derecho de autor y derechos conexos. Buenos Aires: Unesco.

V Congreso internacional sobre la protección de los derechos intelectuales. (1990). Buenos Aires, Argentina. 